Vol. 3, 2018

\title{
Inflammatory Intestinal Diseases
}

\section{Editors-in-Chief}

Gerhard Rogler - University Hospital, Zurich, Switzerland

Toshifumi Hibi - Kitasato University, Tokyo, Japan

\section{Associate Editors}

Silvio Danese - Humanitas University, Rozzano (MI), Italy

Hans Herfarth - University of North Carolina, Chapel Hill, USA

Pin-Jin Hu - Sun Yat Sen University, Guangzhou, China

Beat Müllhaupt - University Hospital, Zurich, Switzerland

Zhihua Ran - Shanghai Jiao Tong University, Shanghai, China

Dario Sorrentino - Virginia Tech-Carilion School of Medicine, Roanoke, USA

Stephan Vavricka - Zentrum für Gastroenterologie und Hepatologie, Zurich,

Switzerland

Hsiu-Po Wang - National Taiwan University, Taipei, Taiwan

Mamoru Watanabe - Tokyo Medical and Dental University, Tokyo, Japan

Ming-Shiang Wu - National Taiwan University, Taipei, Taiwan

Suk-Kyun Yang - University of Ulsan College of Medicine, Seoul, Korea

\section{Editorial Board}

Andre G. Buret - University of Calgary, Calgary, Canada

Jae Hee Cheon - Yonsei University College of Medicine, Seoul, Korea

Linda Chia-Hui Yu - National Taiwan University College of Medicine, Taipei, Taiwan

Andrew S. Day - University of Otago, Christchurch, New Zealand

Devendra Desai - P.D. Hinduja National Hospital \& Medical Research Centre

Veer Savarkar Marg, Mumbai, India

Affiliated with

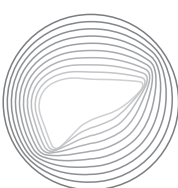

INTERNATIONAL CONFERENCE ON

FATTY LIVER
Iris Dotan - Beilinson Hospital, Petah Tikva, Israel

Richard Gearry - Department of Medicine University of Otago,

Christchurch, New Zealand

Tadakazu Hisamatsu - Kyorin University School of Medicine, Tokyo, Japan

Arthur Kaser - University of Cambridge, Cambridge, UK

Lawrence Khek-Yu Ho - National University, Singapore, Singapore

Taku Kobayashi - Kitasato University, Tokyo, Japan

Kaija-Leena Kolho - University of Helsinki, Helsinki, Finland 


\section{Inflammatory \\ Intestinal Diseases}

(Continued)

Tsung-Chun Lee - National Taiwan University, Taipei, Taiwan

Ling Khoon Lin - Singapore General Hospital, Singapore, Singapore

Toshiyuki Matsui - Fukuoka University Chikushi Hospital, Fukuoka, Japan

Katsuyoshi Matsuoka - Tokyo Medical and Dental University, Tokyo, Japan

Siew C. Ng - Chinese University of Hong Kong, Hong Kong, China

Jiaming Qian - Peking Union Medical College Hospital, Peking, China

Michael Scharl - University Hospital Zurich, Zurich, Switzerland

Ala Sharara - American University of Beirut Medical Center, Beirut, Lebanon

Yasuo Suzuki - Toho University Medical Center Sakura Hospital, Chiba, Japan

Tomohisa Takagi - Kyoto Prefectural University of Medicine, Kyoto, Japan

Kenji Watanabe - Hyogo College of Medicine, Nishinomiya, Japan

Jan Wehkamp - University Hospital and the Faculty of Medicine, Tübingen, Germany

Byong Duk Ye - Asan Medical Center, Seoul, Korea

Qing Zheng - Shanghai Jiao Tong University School of Medicine, Shanghai, China 
S. Karger

Medical and Scientific Publishers

Basel $\cdot$ Freiburg $\cdot$ Hartford $•$ Oxford $•$ Bangkok $\cdot$ Dubai $\cdot$ Kuala Lumpur $\cdot$ Melbourne $\cdot$ Mexico City $\cdot$ Moscow $•$ New Delhi $\bullet$ Paris $\bullet$ Shanghai $\bullet$ Tokyo

\section{Disclaimer}

The statements, opinions and data contained in this publication are solely those of the individual authors and contributors and not of the publisher and the editor(s). The appearance of advertisements in the journal is not a warranty, endorsement, or approval of the products or services advertised or of their effectiveness, quality or safety. The publisher and the editor(s) disclaim responsibility for any injury to persons or property resulting from any ideas, methods, instructions or products referred to in the content or advertisements.

Drug Dosage

The authors and the publisher have exerted every effort to en sure that drug selection and dosage set forth in this text are in accord with current recommendations and practice at the time of publication. However, in view of ongoing research, changes in government regulations, and the constant flow of information relating to drug therapy and drug reactions, the reader is urged to check the package insert for each drug for any change in indications and dosage and for added warnings and precautions. This is particularly important when the recommended agent is a new and/or infrequently employed drug.
All rights reserved.

No part of this publication may be translated into other languages, reproduced or utilized in any form or by any means, electronic or mechanical, including photocopying, recording, microcopying, or by any information storage and retrieval system, without permission in writing from the publisher or, in the case of photocopying, direct payment of a specified fee to the Copyright Clearance Center (see "General Information")

(c) Copyright 2018/2019 by S. Karger AG,

CH-4009 Basel (Switzerland)

Printed on acid-free and non-aging paper (ISO 9706)

\section{KARGER}


No. 1

Reviews

1 Prevention of Infectious Diseases due to Immunosuppression and Vaccinations in Asian Patients with Inflammatory Bowel Disease Sagami, S.; Kobayashi, T.; Hibi, T. (Tokyo)

11 Vaccinations in Adult Patients with Inflammatory Bowel Diseases in the West

Kochar, B.; Herfarth, H.H. (Chapel Hill, NC)

Original Papers

16 A Simple Noninvasive Score Predicts Disease Activity and Deep Remission in Ulcerative Colitis

Hanafy, A.S.; Monir, M.H.; Abdel Malak, H.; Desoky Aiad, M. (Zagazig)

25 Drug Lag for Inflammatory Bowel Disease Treatments in the East and West

Okabayashi, S.; Kobayashi, T.; Hibi, T. (Tokyo)

32 Annual Incidence and Phenotypic Presentation of IBD in Southern New Zealand: An 18-Year Epidemiological Analysis

Coppell, K.J.; Galts, C.P.-C.; Huizing, F.Y.; Norton, J.K.; Gray, A.R.; Schultz, K.; Hobbs, C.E.; Aluzaite, K.; Schultz, M. (Dunedin)

40 Increasing Pediatricians' Awareness of the Association between Anal Skin Tags and Earlier Diagnosis of Crohn's Disease

Korelitz, B.I.; Partiula, B.; Teagle, K.; Swaminath, A.; Schneider, J.; Ellington, M.; Stoffels, G. (New York, NY)

43 Patient Preference and Physician Perceptions of Patient Preference for Oral Pharmaceutical Formulations: Results from a Real-Life Survey MacKenzie-Smith, L.; Marchi, P.; Thorne, H.; Timeus, S. (Rheinfelden); Young, R.; Le Calvé, P. (Paris)

\section{No. 2}

Editorial

53 Diverticular Disease of the Colon

Sharara, A.I. (Beirut)

Diverticular Disease: Reviews

55 The Pathophysiology of Colonic Diverticulosis: Inflammation versus Constipation?

Elisei, W. (Albano Laziale); Tursi, A. (Andria)

61 The Burden of Diverticular Disease and Its Complications: West versus East

Imaeda, H. (Saitama); Hibi, T. (Tokyo)

69 The Natural History of Colonic Diverticulosis: Much Ado about Nothing?

Rustom, L.B.O.; Sharara, A.I. (Beirut)

75 Antibiotics in Uncomplicated Acute Diverticulitis: To Give or Not to Give?

Rezapour, M. (San Francisco, CA); Stollman, N. (Oakland, CA)

80 The Multidisciplinary Management of Acute Complicated Diverticulitis

Lambrichts, D.P.V. (Rotterdam/Amsterdam); Birindelli, A. (Bologna/Birmingham); Tonini, V. (Bologna); Cirocchi, R. (Perugia); Cervellera, M. (Bologna); Lange, J.F. (Rotterdam/ Capelle aan den IJssel); Bemelman, W.A. (Amsterdam); Di Saverio, S. (Bologna/Cambridge)

91 Recurrent Acute Diverticulitis: When to Operate? Al Harakeh, H. (Beirut); Paily, A.J. (Norwich); Doughan, S. (Beirut); Shaikh, I. (Norwich)

100 Management of Diverticular Hemorrhage: Catching That Culprit Diverticulum Red-Handed!

Mizuki, A. (Yokohama); Tatemichi, M. (Isehara); Nagata, H. (Yokohama)

\section{KARGER}

E-Mail karger@karger.com www.karger.com
๑) 2018 S. Karger AG, Basel

Access to full text and tables of contents, including tentative ones for forthcoming issues: www.karger.com/iid_issues 
No. 3

Original Papers

107 The Detergent Effect of Mesalazine Interferes with Phosphatidylcholine Binding to Mucin 2

Stremmel, W.; Staffer, S. (Heidelberg); Gehrke, S. (Baden-Baden)

116 Tacrolimus Suppositories in Therapy-Resistant Ulcerative Proctitis

Jaeger, S.U. (Stuttgart); Klag, T. (Tübingen); Hoeger, K.; Klumpp, S. (Stuttgart); Escher, M. (Leonberg); Malek, N.; Stange, E.; Wehkamp, J. (Tübingen)

125 Human Endogenous Retroviruses: Residues of Ancient Times Are Differentially Expressed in Crohn's Disease Klag, T.; Courth, L. (Tübingen); Ostaff, M.J.; Ott, G. (Stuttgart); Stange, E.F.; Malek, N.P. (Tübingen); Seifarth, W. (Mannheim); Wehkamp, J. (Tübingen)

138 Accommodations and Adaptations to Overcome Workplace Disability in Inflammatory Bowel Disease Patients: A Systematic Review

Paulides, E. (Christchurch/Amsterdam); Gearry, R.B. (Christchurch); de Boer, N.K.H.; Mulder, C.J.J. (Amsterdam); Bernstein, C.N. (Winnipeg, MB); McCombie, A.M. (Christchurch)

145 Dysbiosis of the Gut Microbiota on the Inflammatory Background due to Lack of Suppressor of Cytokine Signalling-1 in Mice

Gendo, Y.; Matsumoto, T.; Kamiyama, N.; Saechue, B.; Fukuda, C.; Dewayani, A.; Hidano, S.; Noguchi, K.; Sonoda, A.; Ozaki, T.; Sachi, N.; Hirose, H.; Ozaka, S.; Eshita, Y.; Mizukami, K.; Okimoto, T.; Kodama, M.; Yoshimatsu, T.; Nishida, H.; Daa, T.; Yamaoka, Y.; Murakami, K.; Kobayashi, T. (Yufu)
No. 4

Reviews

155 Making a Positive Diagnosis of Intestinal Tuberculosis with the Aid of New Biologic and Histologic Features: How Far Have We Reached?

Mehta, V.; Desai, D.; Abraham, P.; Rodrigues, C. (Mumbai)

161 Gastric Diverticulum: A Comprehensive Review Shah, J.; Patel, K. (Newark, NJ); Sunkara, T. (Des Moines, IA); Papafragkakis, C. (Athens); Shahidullah, A. (New York, NY)

Original Papers

167 Risk Factors for Mortality in Pneumocystis jirovecii Pneumonia in Patients with Inflammatory Bowel Disease

Yoshida, A. (Kamakura); Kamata, N. (Osaka); Yamada, A. (Tokyo); Yokoyama, Y. (Nishinomiya); Omori, T.; Fujii, T. (Tokyo); Hayashi, R. (Hiroshima); Kinjo, T. (Nishihara); Matsui, A. (Tokyo); Fukata, N. (Hirakata); Takahashi, S. (Takamatsu); Sakemi, R. (Kitakyushu); Ogata, N. (Yokohama); Ashizuka, S. (Miyazaki); Bamba, S. (Otsu); Ooi, M. (Kobe); Kanmura, S. (Kagoshima); Endo, K. (Sendai); Yoshino, T. (Osaka); Tanaka, H. (Sapporo); Morizane, T. (Kamakura); Shinzaki, S. (Suita); Kobayashi, T. (Tokyo)

173 Bariatric Surgery Is a Safe and Effective Option for Patients with Inflammatory Bowel Diseases: A Case Series and Systematic Review of the Literature Hudson, J.L.; Barnes, E.L.; Herfarth, H.H.; Isaacs, K.L.; Jain, A. (Chapel Hill, NC)

180 Increased Prevalence of Esophageal Eosinophilia in Patients with Inflammatory Bowel Disease

Fan, Y.C.; Steele, D.; Kochar, B.; Arsene, D.; Long, M.D.; Dellon, E.S. (Chapel Hill, NC)

187 Subclinical Nasal and Lung Lymphocytosis in Ulcerative Colitis

Marvisi, M.; Balzarini, L.; Mancini, C.; Ramponi, S.; Marvisi, C.; Maffezzoni, E. (Cremona)

192 Detailed Multi-Dimensional Assessment of Fatigue in Inflammatory Bowel Disease

Aluzaite, K.; Al-Mandhari, R.; Osborne, H.; Ho, C.; Williams, M.; Sullivan, M.-M.; Hobbs, C.E.; Schultz, M. (Dunedin) 
